\title{
Breast cancer in Iraq is associated with a unimodally distributed predominance of luminal type $B$ over luminal type $A$ surrogates from young to old age
}

\author{
Runnak A Majid', Hemin A Hassan', Dana N Muhealdeen', Hazha A Mohammed² and Michael D Hughson ${ }^{\text {* }}$
}

\begin{abstract}
Background: Breast cancer has recently increased in post-menopausal Iraqi women. In Western countries at highrisk for breast cancer, there is a bimodal increase in estrogen receptor (ER) positive tumors with a peak of low proliferation rate luminal A over higher proliferation rate luminal B tumors after 60 years of age. The aim of this study was to analyze in Iraqi women whether shifts are occurring in immunohistochemical (IHC) surrogates of molecular breast cancer subtypes toward a high-risk profile.
\end{abstract}

Methods: Age specific and age standardized womens breast cancer incidence was estimated for the years 2006 through 2012. IHC results of ER, PR, HER2, and Ki67 testing were analyzed on the breast cancers of 125 Arabic and 725 Kurdish women by frequency of distribution and by age.

Results: Between 2006 and 2012, age standardized incidence of breast cancer in Iraq increased from 30 to 40/ 100,000 women with the increase specifically occurring in women $\geq 60$ years old $(P<0.001)$. Breast cancers in Kurdish women $\geq 60$ years old may also have increased $(P=0.047)$ with urban exceeding rural rates by 2:1. For both Kurdish and Arabic women, there was a marked predominance of luminal B tumors at all ages in which luminal $B$ and luminal A tumors were asymmetric skewed toward older age but with no late luminal A age peak.

Conclusions: Older Iraqi women do not show the bimodal shift toward higher rates of luminal A breast cancers seen in the West. The modest increase in age standardized incidence of breast cancer in Iraqi is being seen specifically in older women and may be better attributed to a trend for care in urban cancer centers rather than changing tumor characteristics.

Keywords: Breast cancer, Iraq, Cancer incidence, Breast cancer receptors, Luminal A and luminal B breast cancer, Middle-East

\section{Background}

In the developing world, cancer is projected to increase by $70 \%$ over the next $20-25$ years. Breast cancer represents $20-30 \%$ of cancer among women and is likely to account for a major part of that increase [1]. These expectations are anticipated because the populations of developing countries are ageing and cancer is largely a disease of older people. Life-style changes are likely to contribute,

\footnotetext{
* Correspondence: muhghson@bellsouth.net

'Department of Pathology, Shorsh General Hospital and the Hiwa Regional

Oncology Center, Qirga Road, 46001 Sulaimaniyah, Kurdistan, Iraq

Full list of author information is available at the end of the article
}

because transitions from a traditional to a Westernized life-style expose women to higher individual risk [2].

The world can be divided into low-risk and high-risk regions on the basis of differences in breast cancer incidence $[1,2]$. Those at high-risk consists of the developed countries of Northern Europe, North American, Uruguay, Argentina, Australia and New Zealand. In these areas, age standardized incidence exceeds 80-100/100,000 women. In the developing world, age standardized incidence (ASI) varies from 20-60/100,000 women, and in parts of Central and Southeast Asia and sub-Saharan Africa, estimates are less than 20/100,000 [1,2]. 
Breast cancer in all parts of the world begins to be seen at about 20 years of age [3]. Afterward, age specific incidence steadily rises until the menopause when geographic differences begin to be seen. In the developing world, a flattening and then a decline occur about 10-15 years after the menopause. In developed countries, the age specific incidence accelerates after the menopause, and at age 70 and above doubles that seen at 45-49 years old [3-5]. The life-style changes contributing to increased post-menopausal breast cancer are largely premenopausal and include obesity, low rates of childbirth, infrequent or no lactation, early menarche, and late menopause [2]. These factors, that are common in highrisk countries, promote a state of relative hyperestrogenism and the development of estrogen responsive tumors [3-5]. The life-style factors are becoming more common in countries considered low-risk particularly in their growing urbanized communities [6].

Molecular subtyping has defined at least four categories of breast cancer with the most prevalent type and that being most closely related to increased estrogen exposure being estrogen receptor (ER) positive and negative for the Her-2-neu (HER2) proto-oncogene [3]. ER positive tumors are further subtyped into low proliferation rate luminal $\mathrm{A}$ and higher proliferation rate luminal B tumors with the luminal A tumors being more frequently seen in older women in regions of the world at high-risk for breast cancer [3].

Breast cancer rates in Iraq and its Kurdish region were generally stable between 2000 to 2009, but newer data from the Iraqi Cancer Registry reveal rising rates since 2009 with women after age 50 making the major contribution to the increase [5, 7-9]. In this study, demographic changes are explored together with tumor ER and HER2 subtyping. The aim of the study was to determine whether age related shifts may be occurring in ER and HER2 subtypes that may offer insight into potential increases of breast cancers in culturally transitional Middle-Eastern countries.

\section{Methods \\ Calculation of age specific and age standardized incidence}

Data for the country of Iraq were obtained from the publications of the Iraqi Cancer Registry for the years 2006 and 2012 [9, 10]. These publications provided detailed information regarding the age specific incidence rates of breast cancer and the female population of Iraq in the 5-year age ranges from 0 to $70+$ years old. The proportions of the population in the 5 year age ranges correspond to that published by the United Nations Population Division (population pyramid.net).

Data for Sulaimaniyah were obtained from the Hiwa Regional Oncology Center cancer registry. The data collection was limited to the years before 2014 so as to not be influenced by the large recent influx of internally displaced persons into the Kurdish region. Breast cancers for Sulaimaniyah were averaged for the three year periods 2006-2008 and 2011-2013. The 2006 and 2012 Sulaimaniyah populations were obtained from the Iraqi Cancer Registry and matched with the population estimates from the Sulaimaniyah Department of Statistics. The 5 year age distribution followed the proportions used for all of Iraq.

For each region, age specific incidence rates were calculated on the basis of the number of cancers per 100,000 women in the specified age ranges. Age standardized incidence rates were calculated using the WHO World Standard population.

\section{Analysis of breast cancer subtypes}

Immunohistochemistry (IHC) for ER, progesterone (PR), HER2, Ki67, and HER2 FISH for IHC equivocal HER2 cases was performed for breast cancers of Hiwa Hospital patients at the Shorsh Hospital Pathology Department. Details of the technical procedures have been previously published [5]. The luminal A subtype was defined as ER +/HER2- with a KI67 index $\leq 20 \%$ and PR+ with an Allred PR score $\geq 4$; the luminal B subtype was defined as an ER+ and/or PR+ tumor, \pm HER2+, and with a Ki67 index $>20 \%$ [11-14].

\section{Statistical methods}

Data was entered into an Excel worksheet and analyzed with Stata IC10 ${ }^{\mathrm{m}}$ (Stata Corp, College Station, TX) and SigmaStat 3.5 (Systat Software Inc., San Jose, CA) statistical software. Changes in breast cancer incidence in the years 2001 to 2012 were analyzed by Poisson's regression for the age ranges $20-39,40-49,50-59$, and $60+$ years old [15]. Differences between groups were tested by Kruskall-Wallace analysis of variance (ANOVA) on ranks with Dunn's post-hoc pairwise tests. Age by ethnicity was normally distributed for some receptor subtypes but not others, and two-way comparisons used Wilcoxon rank-sum tests. For all statistical procedures $P<$ 0.05 was considered significant.

\section{Results}

Age distribution of Iraqi and Sulaimaniyah populations

The Sulaimaniyah population estimates and incidence rates are for ethnic Kurdish women only. Table 1 specifies in 5-year age ranges the raw data for female populations and the numbers of women's breast cancers for the years 2001, 2006, and 2012 for Iraq. There is no data available for Sulaimaniyah in 2001, and only 2006 and 2012 are shown. 
Table 1 The womens population and the numbers of breast cancers in Sulaimaniyah and all of Iraq by 5 year age groups

\begin{tabular}{|c|c|c|c|c|c|c|c|c|c|c|}
\hline & Sulaimar & & & & Iraq & & & & & \\
\hline & 2006 & & 2012 & & 2001 & & 2006 & & 2012 & \\
\hline & pop & $B C$ & pop & $B C$ & pop & $B C$ & pop & $B C$ & pop & $B C$ \\
\hline $0-4$ & 129187 & 0 & 136092 & 0 & 1843227 & 0 & 2352412 & 0 & 2365695 & 0 \\
\hline $5-9$ & 120025 & 0 & 126440 & 0 & 1586575 & 0 & 1995955 & 0 & 2192043 & 0 \\
\hline 10-14 & 110863 & 0 & 116788 & 0 & 1423251 & 0 & 1721195 & 2 & 2024941 & 0 \\
\hline $15-19$ & 98036 & 0 & 103276 & 0 & 1259927 & 5 & 1530129 & 6 & 1800966 & 1 \\
\hline $20-24$ & 84292 & 1 & 88798 & 1 & 1119935 & 14 & 1312396 & 18 & 1551925 & 26 \\
\hline $25-29$ & 69633 & 4 & 73355 & 4 & 956611 & 66 & 1125539 & 55 & 1282305 & 76 \\
\hline 30-34 & 61387 & 11 & 64668 & 14 & 816619 & 121 & 953623 & 136 & 1129203 & 203 \\
\hline $35-39$ & 55890 & 21 & 58877 & 19 & 583300 & 244 & 794087 & 272 & 1026864 & 355 \\
\hline $40-44$ & 48560 & 28 & 51155 & 41 & 466640 & 334 & 638097 & 388 & 884658 & 610 \\
\hline $45-49$ & 40314 & 30 & 42469 & 37 & 419976 & 386 & 514935 & 412 & 738741 & 677 \\
\hline $50-54$ & 28403 & 28 & 29921 & 28 & 279984 & 345 & 399765 & 441 & 522486 & 582 \\
\hline $55-59$ & 21989 & 26 & 23165 & 26 & 233320 & 201 & 310221 & 262 & 403572 & 481 \\
\hline $60-64$ & 19241 & 11 & 20269 & 18 & 209988 & 175 & 228969 & 214 & 358341 & 426 \\
\hline $65-69$ & 10995 & 11 & 11582 & 12 & 193324 & 107 & 166953 & 141 & 205681 & 252 \\
\hline $70+$ & 16492 & 9 & 17373 & 15 & 256652 & 122 & 272958 & 155 & 300103 & 333 \\
\hline
\end{tabular}

Legend: The breast cancers for Sulaimaniyah represent the averages for the three year periods 2006-2008 and 2010-2013. For Iraq, the numbers are for the indicated year. The year is designated by the availability of population data within the period that the breast cancers were enumerated. Abbreviations:

Pop,population, $B C$ breast cancer

\section{Age standardized and age specific incidence}

Table 2 demonstrates the age specific incidence rates in the regions and the changes over the period from 2001 to 2012. Prior to 2012, the age standardized rates were approximately 30 per 100,000 women with a peak age specific incidence at 50-54 years old and a declining rate in older age groups. At 70+ years old, rates were similar to those seen at 35-39 years of age. In all of Iraq in 2012, age specific incidence exceeded 110/100,000 for all 5 -year age groups from 50 to $70+$ years old, and the age standardized rate increased to $40 / 100,000$. In Sulaimaniyah, age standardized incidence increased slightly from 32 to 36/100,000 between 2006 and 2012 .

\section{Distribution of breast cancer by age}

By Poissons regression, in all of Iraq over the decade 2001-2012, there was a significantly increased breast cancer rate between 2006 and 2012 among women $\geq$ 60 years old $(\mathrm{P}<0.001)$ but not in younger age groups (Table 3). Table 3 also indicates that for Sulaimaniyah, breast cancer rates may also have increased in the $\geq$ 60 year old age group $(P=0.047)$.

\section{Rural vs urban differences}

We attempted to look at urban vs rural differences in breast cancer rates. Data from Baghdad were not available. In 2011-2013, 63.1\% of Sulaimaniyah breast cancer patients identified themselves as living in the central city (3-year average, central city 137 patients vs other
Table 2 Age specific incidence per 100,000 women in five-year age groups for Sulaimaniyah and all of Iraq for the indicated years

\begin{tabular}{lllllll}
\hline & \multicolumn{2}{l}{ Sulaimaniyah } & & Iraq & \\
\cline { 2 - 3 } \cline { 5 - 6 } Age (yrs) & 2006 & 2012 & & 2001 & 2006 & 2012 \\
\hline $0-4$ & 0 & 0 & & 0 & 0 & 0 \\
$5-9$ & 0 & 0 & & 0 & 0 & 0 \\
$10-14$ & 0 & 0 & 0 & 0 & 0 \\
$15-19$ & 0 & 0 & & 0 & 0 & 0 \\
$20-24$ & 1 & 2 & & 1 & 1 & 2 \\
$25-29$ & 6 & 6 & & 7 & 5 & 6 \\
$30-34$ & 18 & 22 & & 15 & 14 & 18 \\
$35-39$ & 38 & 32 & & 42 & 34 & 35 \\
$40-44$ & 57 & 81 & & 72 & 61 & 69 \\
$45-49$ & 74 & 88 & & 92 & 80 & 92 \\
$50-54$ & 99 & 95 & & 123 & 110 & 111 \\
$55-59$ & 117 & 113 & & 86 & 85 & 119 \\
$60-64$ & 56 & 89 & & 83 & 94 & 119 \\
$65-69$ & 103 & 103 & 66 & 85 & 123 \\
$70+$ & 56 & 84 & 48 & 57 & 111 \\
Total rate & 32 & 36 & 33 & 32 & 40 \\
\hline
\end{tabular}

Legend: Rates are rounded to the nearest whole number. The total rate is age standardized using the WHO world standard population (2002) 
Table 3 Poisson regression analysis of the changes in age specific incidence rates in the indicated age ranges over the period from 2001 to 2012 in all of Iraq and over the period 2006 to 2012 for Sulaimaniyah

\begin{tabular}{|c|c|c|c|c|}
\hline \multirow[b]{2}{*}{ Age (years) } & \multicolumn{2}{|l|}{ Sulaimaniyah } & \multicolumn{2}{|l|}{ Iraq } \\
\hline & coefficient & P & coefficient & $P$ \\
\hline $20-39$ & $0.000(-0.148$ to 0.148$)$ & 1.000 & $0.000(-0.078$ to 0.078$)$ & 1.000 \\
\hline $40-49$ & $0.051(-0.013$ to 0.116$)$ & 0.12 & $-0.003(-0.034$ to 0.029$)$ & 0.87 \\
\hline $50-59$ & $-0.008(-0.062$ to 0.046$)$ & 0.78 & 0.008 (-0.018 to 0.035$)$ & 0.54 \\
\hline $60+$ & 0.064 (0.001 to 0.128$)$ & 0.047 & 0.063 (0.032 to 0.094$)$ & $<0.00$ \\
\hline
\end{tabular}

governate 80 patients). In 2012, the central city of Sulaimaniyah was estimated to have a population of 867,000 (433,500 women) (www.theodora.com/wfbcurrent/iraq/ iraq_people.html). This would provide a crude incidence of 31.6/100,000 for the central city and 15.0/100,000 for women from the outlying areas of the Governate.

\section{Breast cancer subtypes by age and ethnicity}

In the years 2011-2013, 850 primary breast cancers from Hiwa Hospital patients (725 Kurdish and 125 Arabic) were analyzed. The average age of Kurdish patients was $48.9 \pm 11.9$ and Arabic patients $49.3 \pm$ 11.5 years, a not significant difference $(P=0.72)$. For Kurdish and Arabic patients combined, the distribution by ER+/HER2-, ER+/HER2+, ER-/HER2+, triple negative, and luminal $\mathrm{A}$ and luminal $\mathrm{B}$ subtypes in the age ranges 20-39, 40-49, 50-59, and 60+ years old are shown in Table 4 . The great majority of tumors were ER +/HER2- (64.8\%) but with the luminal A cancers representing just $27.4 \%$ and luminal B nearly twice that number at $46.8 \%$ of subtypes. Triple negative comprised $12.8 \%$ and ER-/HER $2+13.0 \%$ of tumors. Figures 1 and 2 are kernel density plots by age for the major subtypes. Figure 1 reveals an earlier onset of ER+/HER2+ (luminal $\mathrm{A} / \mathrm{HER}+$ ) and triple negative compared to ER+/HER2and ER-/HER2+ tumors. ER+/HER2- tumors showed a pronounced skew into older age, but all subtypes overlapped with no significant differences in age between patients with ER+/HER2-, ER-/HER2+, and triple negative tumors (ANOVA, $P>0.05$ ). The proportional diagnoses of receptor types by Kurdish or Arab ethnicity were not significantly different (ER+/HER2-, 457 vs 85; ER+/HER2+, 68 vs 11; ER-/HER2+, 98 vs 11; triple-, 90 vs $17 ; X^{2}=2.40, P=0.49$ ), and ethnicity versus age was not statistically different for any receptor type (Table 5).

\section{Age and ethnic distribution of luminal A and luminal B tumors}

Figure 2 shows that luminal B/HER2- tumors began to be seen at an earlier age than Luminal A tumors, but both subtypes were closely nested over the entire range of young to old age with no suggestion of a late luminal A peak. Luminal B/HER $2+$ tumors had a significantly earlier peak than the other subtypes $(P<0.01)$. Although Luminal B/HER2+ tumors represented only $28 \%$ of all luminal B tumors, the earlier age contributed to all luminal B tumors being found at a significantly earlier age than luminal A tumors $(P=0.04)$ but with no significant difference in age between luminal $A$ and luminal B/HER2- tumors $(P=0.19)$. Figure 3 plots age specific incidence per 100,000 women for the major subtypes. The peak incidence of all cancers was about 60 years of age but then declined markedly from 60 to 80 years old. The decline includes luminal $\mathrm{A}$ and luminal B subtypes with the incidence of luminal B exceeding that of luminal $\mathrm{A}$ at all ages (Fig. 4).

Table 4 Sulaimaniyah ER and HER2 breast cancer subtypes by age groups, Kurdish and Arabic

\begin{tabular}{|c|c|c|c|c|c|c|}
\hline Age (years) & $\mathrm{ER}+/ \mathrm{HER2}-$ & ER+/HER2+ & ER-/HER2+ & Triple- & Luminal A & Luminal B \\
\hline 20-39 & 97 & 19 & 30 & 28 & 23 & 67 \\
\hline $40-49$ & 189 & 33 & 30 & 31 & 64 & 96 \\
\hline $50-59$ & 146 & 18 & 27 & 26 & 39 & 57 \\
\hline $60+$ & 110 & 9 & 22 & 22 & 30 & 48 \\
\hline All (\%) & $542(64.8)$ & $79(9.4)$ & 109 (13.0) & 107 (12.8) & $156(27.4)^{*}$ & $268(46.8)^{*}$ \\
\hline Ave age & $49.7 \pm 11.7$ & $46.2 \pm 11.0^{\mathrm{a}}$ & $47.3 \pm 10.4$ & $48.8 \pm 13.2$ & $49.7 \pm 10.7^{b}$ & $47.6 \pm 11.3$ \\
\hline Ki67 & $26.1 \pm 18.6^{c}$ & $39.9 \pm 21.0$ & $43.1 \pm 23.0$ & $56.6 \pm 26.5^{c}$ & $11.6 \pm 5.0$ & $37.9 \pm 18.4$ \\
\hline
\end{tabular}

Legend: *Luminal A and luminal B are derived from ER+/HER2- and ER+/HER2+ tumors that had Ki67 testing with the percentages being extrapolated to the sum of all subtypes. The number of luminal A and Luminal B tumors $(n=424)$ does not correspond to the number of ER+/HER2- and ER+/HER2+ tumors ( $n=621)$, because not all of the later had Ki67 testing. The age of ER+/HER2+ patients is significantly different than ER+/HER2- patients $(P<0.01)^{\mathrm{a}}$. The age of luminal $A$ patients is significantly different than luminal B patients $(P=0.04)^{\mathrm{b}}$. The Ki67 of ER+/HER2- and triple- breast cancers are significantly different than other subtypes $(P<0.001)^{\mathrm{c}}$ 


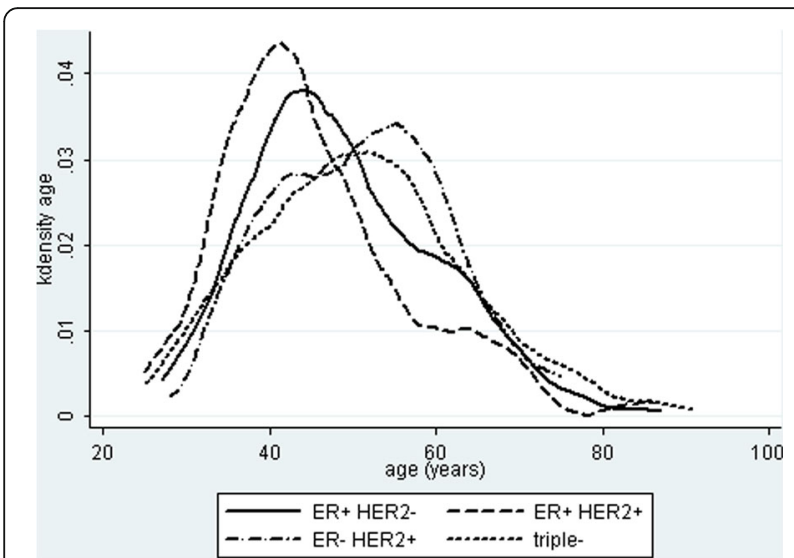

Fig. 1 Kernal density plots for the four major ER and HER2 subtypes Legend: ER+/HER2+ tumors peak at a significantly earlier age than ER+/HER2- tumors $(P<0.01)$. There is no significant difference in the age distribution of other subtypes (ANOVA, $P>0.05$ )

\section{Discussion}

Molecular breast cancer subtyping is widely used clinically to identify patients at low risk for metastasis and can be roughly inferred on the basis of IHC testing [12, 13]. While the 2015 St Gallen's consensus considered the IHC designation of molecular subtypes as being impractical for guiding treatment, the assignment may be valuable from an epidemiologic standpoint $[3,13]$. In the West, the average age of newly diagnosed breast cancer patients is $>$ 60 years old, and the high rates of breast cancer are the result of a several-fold increase in the age specific incidence of ER+/HER2- tumors in post-menopausal women [3-5].

In US women, on the basis of IHC with parallel PAM50 molecular testing, luminal B breast cancers were found to be more common than luminal A tumors by a factor of 2.48 under 40 years of age with the ratio decreasing to 1.27 at $40-49$ years old [16]. At 50-59 years of age, the proportions reached parity, and at $>60$ years old, luminal A exceeded luminal B tumors by $25-50 \%$ [16]. In terms of age specific density, this created a bimodal frequency for ER+ tumors in which there is a minor peak mainly of luminal $B$ tumors at about age 50

Table 5 Comparison of Arab and Kurdish ethnicity versus age for the specified breast cancer receptor types

\begin{tabular}{llll}
\hline Receptor type & Arab $(n)$ & Kurdish $(n)$ & $P$ \\
\hline ER+/HER2- & $48.3 \pm 10.5(85)$ & $49.0 \pm 11.1(457)$ & 0.83 \\
ER+/HER2+ & $48.7 \pm 10.5(11)$ & $44.9 \pm 10.8(79)$ & 0.61 \\
ER-/HER2+ & $51.2 \pm 7.8(11)$ & $1.2 \pm 10.9(98)$ & 0.91 \\
Triple- & $53.7 \pm 18.2(17)$ & $50.7 \pm 12.1(90)$ & 0.81 \\
Luminal A & $51.7 \pm 11.9(15)$ & $49.5 \pm 10.6(141)$ & 0.53 \\
Luminal B & $46.8 \pm 11.2(31)$ & $47.7 \pm 11.4(237)$ & 0.66 \\
\hline
\end{tabular}

Legend: Values are displayed as mean \pm standard deviation. Comparisons are made by Wilcoxon rank sum tests. The receptor subtypes by age were not significantly different between Kurdish or Arabic women

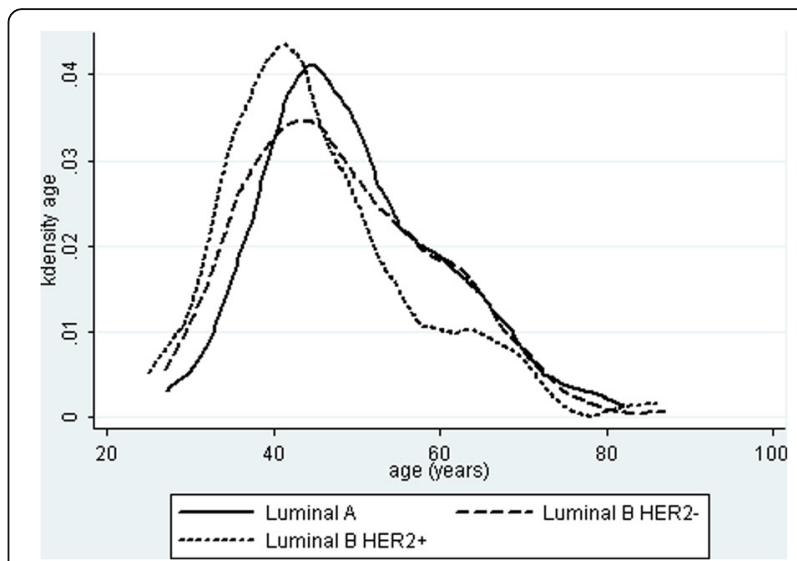

Fig. 2 Kernal density plots of ER+ tumors separated into luminal B HER2+, luminal B HER-, and luminal A tumors

Legend: Luminal B/HER2+ tumors developed first at a significantly earlier age than luminal $A$ tumors $(P<0.01)$. Luminal B/HER2- were found next, but the age distribution was not significantly different than for luminal A tumors $(P=0.19)$

and a major peak due to the late contribution of luminal A tumors near age 70 [3].

This is not seen in Sulaimaniyah for Kurdish or Arab breast cancer patients where the average is $<50$ years old for both ethnic groups. In these Iraqi patients, luminal B tumors were the predominant subtype from the beginning of breast cancer development in the early $20 \mathrm{~s}$ and remained predominant at all later ages. The age distribution of both luminal A and luminal B tumors was unimodal and closely overlapping with no suggestion of a late peak for ER+ tumors.

On the basis of both molecular testing and IHC surrogates, this greater proportion of luminal B over luminal A breast cancers has been observed in other low

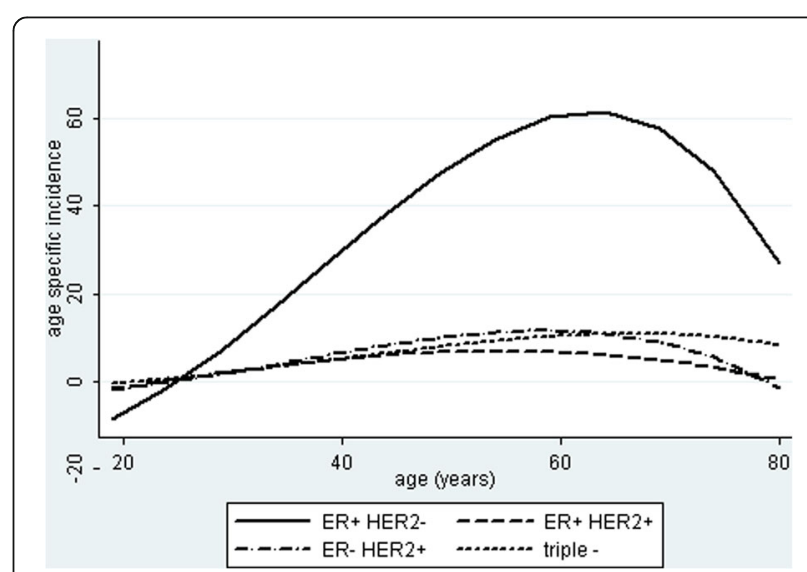

Fig. 3 Age specific incidence of the four major ER and HER2 subtypes

Legend: Polynomial regression plots show a peak incidence predominantly of ER+/HER2- tumors at approximately age 55-60 years that rapidly declines afterward 


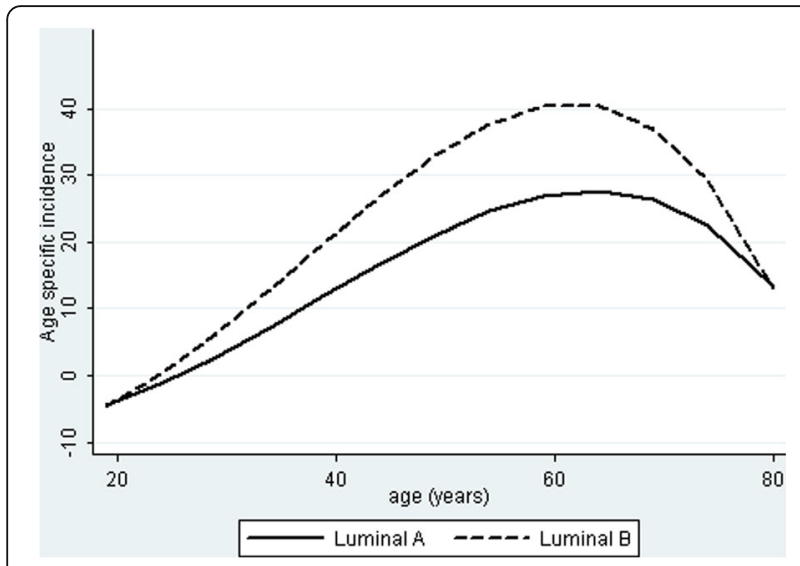

Fig. 4 Age specific incidence of luminal A and luminal B tumors Legend: Polynomial regression plots showing a predominance of luminal $B$ at all ages over luminal $A$ tumors. There is no late luminal A peak that exceeds the incidence of luminal $B$ tumors

incidence countries, including Colombia [age standardized incidence (ASI), 39.7] and China (ASI, 31.7) [17-19]. In reports of Middle-Eastern patients in which luminal A were distinguished from $\mathrm{ER}+/ \mathrm{PR}+$ luminal $\mathrm{B}$ tumors on the basis of a low Ki67 index, a > 3:1 predominance of luminal B over luminal A was found in Saudi Arabia (ASI, 24.7) and in Moroccan Arab immigrants to Belgium [20, 21]. In the Belgium study, Moroccan and European women were compared [21]. The mean age of Moroccan women was 49 \pm 11 years old. European women who averaged 60 years old showed a contrasting all age parity in the proportion of luminal $\mathrm{A}$ and $\mathrm{B}$ tumors.

A 2013 report from Jordan showed that despite an increasing incidence of breast cancer in older women, the median age of all Jordanian breast cancer patients was still 50 years old [22]. The authors claimed a predominance of luminal A tumors, but the cancers were not identified as luminal A based upon the St. Gallen's guidelines and included all luminal subtypes except those that were HER2 positive [22].

The 2013 St Galen's guidelines recommended that luminal A be defined as ER+/PR+/HER2- tumors with a Ki67 index $\leq 14 \%$ and PR expression in $>20 \%$ of cells [12]. Higher proliferation rate ER+ tumors including the triple positive $\mathrm{ER}+/ \mathrm{PR}+/ \mathrm{HER} 2+$ subtype are considered luminal B. The 2015 guidelines suggested a Ki67 index $\leq$ $20 \%$ or a Ki67 index less than the laboratory average for ER+/HER2- tumors [13]. Regardless of the specific Ki67 criteria, a low proliferation rate is needed to reasonably replicate a luminal A molecular phenotype.

In Sulaimaniyah patients, triple negative and ER-/ HER2+ were nearly evenly distributed throughout all age groups at a frequency approximately half that of luminal A tumors. This is representative of triple negative and ER-/HER2+ subtypes in other low incidence countries and illustrates their relatively low contribution to the total breast cancer burden compared to luminal tumors $[5,18,19,23,24]$. Triple negative tumors are unusually common in sub-Saharan and African American women $[3,24,25]$. However, in other racial groups they seem to have a relatively constant frequency of about 10-15\% and increase proportionately across all ages as the general rate of breast cancer rises [3, 5, 17-19, 24-26].

The relatively higher rates of luminal $\mathrm{B}$ breast cancers in developing countries may be a reflection of the younger populations and the relatively small proportions of aging women exposed to premenopausal hyperestrogenism. We have previously reported that the age specific incidence of the common ER+/HER2- breast cancer is similar in Kurdish and US women under 50 years old [5]. The difference in the two populations is the absence in Kurdistan of the marked increase in the rates of ER+/HER2- tumors in older women that is seen in the US [5]. This lends credibility to a concept of a prolonged population exposure being needed for the development of luminal A tumors. Nevertheless, it is worth mentioning that the age of the population by itself is not the determining factor. China has a huge, aging population but a low breast cancer age standardized rate and low rates of luminal A tumors $[17,23]$. In addition, low parity, that is considered a risk factor for post-menopausal tumors in the West, has been public policy in China for decades.

Our findings show that breast cancer incidence was essentially the same in the Kurdish region and in the south of Iraq before 2010 with an age standardized rate of approximately 30 per 100,000 women. After 2009, rates increased to $40.0 / 100,000$ women in the south of Iraq and with a smaller change in Sulaimaniyah. This seems to be following the pattern observed over the past decade in Jordan (ASI, 53.8), Lebanon (ASI, 55.4), and several Gulf States including Kuwait (ASI, 48.0) and Qatar (ASI, 45.0) and may be an early phase in the transition toward higher breast cancer rates [2].

It is not obvious whether the increasing age standardized rate of breast cancer in Iraq and other MiddleEastern countries is a true biological transition or whether it reflects the increased utilization of urban cancer centers $[5,19,26,27]$. With a more general awareness of breast cancer, financially able women may selectively be traveling for a level of care that is not within the means of many families. In 2011, 60.1\% of breast cancer among Jordanian women was diagnosed in Amman where the crude incidence rate was 47.8/ 100,000 [28]. This compared with the outlying Governates where crude incidence varied from 11.7 to 22.7/ 100,000 women. In the Sulaimaniyah Governate, a similar clustering of breast cancer diagnosis was found in central Sulaimaniyah city. This may indicate urban/rural differences in incidence but as likely represents patterns of accessing cancer care. 
The technology and specialization needed for modern cancer care necessitates its centralization but also has the potential for creating demographic artifacts. With mammography and MRI, central facilities have the ability to detect small and in-situ breast cancer that may not be found by clinical practice outside of major centers. In addition, women taking advantage of these facilities may be more likely to have risk factors associated with post-menopausal disease.

In many if not most Middle-East countries, luminal subtypes represent more than $60 \%$ of breast cancers of all ages and more than $70 \%$ after age $60[5,6,20-22,26,27]$. Whether the pattern of increasing rates of breast cancer in older patients is taking a direction that will resemble the West remains to be seen, and it will be valuable to understand the relationships between cancer subtypes in the region. If the Western pattern is followed, age standardized rate should continue to rise, the average age of breast cancer patients should increase, and luminal A should exceed the frequency of luminal B tumors at around $60-70$ years of age.

\section{Conclusions}

Older Iraqi women do not show the bimodal shift toward higher rates of luminal A breast cancers seen in the West. The modestly increased breast cancer rates being seen in some Middle-Eastern countries may be the result of factors different from those occurring in the West and may not represent a transition to high-risk breast cancer rates. As an epidemiological study, the major limitation is that the design is observational and retrospective and that breast cancer subtyping is lacking in Iraq outside of the Kurdish region.

\section{Abbreviations}

ANOVA: Analysis of variance; ASI: Age standardized incidence; ER: Estrogen receptor; HER2: Her-2-neu; IHC: Immunohistochemistry; PR: Progesterone receptor

\section{Acknowledgements}

The authors thank the histology department of Shorsh Pathology laboratory for their extra work in preparing the high quality of sections and immunohistochemistry from the many breast specimens. MDH particularly thanks Mr. Adalan Abdulmajeed Mustafa, the supervisor of medical records at Hiwa Hospital, who tirelessly searched files to confirmed diagnoses and establish the ethnicity and residence of breast cancer patients.

\section{Funding}

The research including purchase of immunohistochemical reagents and technical salary support was sponsored by the Ministry of Health of the Kurdistan Regional Government and the Peshmerga Health Foundation (Dr Runnak, Principal Investigator).

\section{Availability of data and materials}

Compiled data are stored in Excel worksheets in the Shorsh Hospital Department of Pathology and will be made available upon request to the corresponding author $(\mathrm{MDH})$.

\section{Authors contributions}

RAM, HAM, DNM, and HAH contributed to data collection and analysis. RAM wrote the first draft of the manuscript. MDH was the principal contributor toward study design and data analysis. MDH contributed to revisions for the final manuscript that was reviewed and approved by all authors.

\section{Competing interests}

The authors declare that they have no interests that compete with any of the contents of the manuscript.

\section{Consent for publication}

Data was used in aggregate with no personal identifiers and required no consent for publication.

\section{Ethics approval and consent to participate}

The ethics committee of the Sulaimaniyah Directorate of Health under Dr Miran Mohammed gave permission for the research. The research was conducted according to the Helsinki Accords. The research involved a review of existing medical and pathology records. It involved no intervention requiring patient approval beyond that required for standard diagnostic and therapeutic procedures.

\section{Publisher's Note}

Springer Nature remains neutral with regard to jurisdictional claims in published maps and institutional affiliations.

\section{Author details}

'Department of Pathology, Shorsh General Hospital and the Hiwa Regional Oncology Center, Qirga Road, 46001 Sulaimaniyah, Kurdistan, Iraq.

${ }^{2}$ Department of Oncology, Hiwa Regional Oncology Center, Sulaimaniyah, Kurdistan, Iraq.

Received: 18 August 2016 Accepted: 4 March 2017

Published online: 07 April 2017

\section{References}

1. American Cancer Society. Global cancer facts and figures. 2nd ed. Atlanta: American Cancer Society; 2011

2. Jemal A, Bray F, Center MM, Ferlay J, Ward E, Forman D. Global cancer statistics. CA Cancer J Clin. 2011;61:69-90.

3. Anderson WF, Rosenberg PS, Prat A, Perou CM, Sherman ME. How many etiologic subtypes of breast cancer: two, three, four, or more? J Natl Cancer Inst 2014;106:dju 165.

4. Rennert G. Breast cancer. In cancer incidence in the four member countries (Cyprus, Egypt, Isreal, Jordan) of the Middle-East Cancer Consortium (MECC) compared with US SEER, Chapter 8. Edited by Friedman LS, Edwards BK, Reiss LAG, Young JL. Bethesda, MD: National Cancer Institute. NIH pub no. 06-5873; 2006:73-81.

5. Runnak MA, Hazha MA, Hemin HA, Wassan AA, Rekawt RM, Michael HD. A population based study of Kurdish breast canecr in Northern Iraq: hormone receptor and HER2 status. A comparison with Arabic women and United States SEER data. BMC Womens Health. 2012;12:16.

6. Hirko KA, Soliman AS, Hablas A, Seifeldin IA, Ramadan M, Banerjee M, Harford JB, Chamberlain RM, Merajver SD. Trends in Breast Cancer Incidence Rates by Age and Stage at Diagnosis in Gharbiah, Egypt, over 10 Years (1999-2008). J Cancer Epidemiol. 2013;2013:916394.

7. Majid RA, Mohammed HA, Saeed HM, Safar BM, Rashid RM, Hughson MD. Breast cancer in Kurdish women of northern Iraq: incidence, clinical stage, and case control analysis of parity and family risk. BMC Womens Health. 2009;9:33.

8. Al-Hashimi MM, Wang XJ. Breast cancer in Iraq, incidence trends from 2000-2009. Asian Pac J Cancer Prev. 2014;15:281-6.

9. Iraqi Cancer Registry 2006. Iraqi Cancer Board, Ministry of Health, Republic of Iraq, 2010.

10. Iraqi Cancer Registry 2012. Iraqi Cancer Board, Ministry of Health, Republic of Iraq, 2014

11. Maisonneuve P, Disalvatore D, Rotmensz N, Curigliano G, Colleoni M, Dellapasqua S, Pruneri G, Mastropasqua MG, Luini A, Bassi F, Pagani G, Viale G, Goldhirsch A. Proposed new clinicopathological surrogate definitions of luminal A and luminal B (HER2-negative) intrinsic breast cancer subtypes. Breast Cancer Res. 2014;16:R65. 
12. Goldhirsch A, Winer EP, Coates AS, Gelber RD, Piccart-Gebhart M, Thürlimann B, Senn HJ, Panel members. Personalizing the treatment of women with early breast cancer: highlights of the St Gallen International Expert Consensus on the Primary Therapy of Early Breast Cancer 2013. Ann Oncol. 2013;24:2206-23.

13. Coates AS, Winer EP, Goldhirsch A, Gelber RD, Gnant M, Piccart-Gebhart M, Thürlimann B, Senn HJ, Panel Members. Tailoring therapies-improving the management of early breast cancer: St Gallen International Expert Consensus on the Primary Therapy of Early Breast Cancer 2015. Ann Oncol. 2015;26:1533-46.

14. Bustreo S, Osella-Abate S, Cassoni P, Donadio M, Airoldi M, Pedani F, Papotti M, Sapino A, Castellano I. Optimal Ki67 cut-off for luminal breast cancer prognostic evaluation: a large case series study with a long-term follow-up. Breast Cancer Res Treat. 2016;157:363-71.

15. Ghosh P, Gosh K, Tiwari RC. Bayesian approach to cancer-trend analysis using age-stratified Poisson Regression models. Stat Med. 2011;30:127-39.

16. Sweeney C, Bernard PS, Factor RE, Kwan ML, Habel LA, Quesenberry Jr CP, Shakespear K, Weltzien EK, Stijleman IJ, Davis CA, Ebbert MT, Castillo A, Kushi LH, Caan BJ. Intrinsic subtypes from PAM50 gene expression assay in a population-based breast cancer cohort: differences by age, race, and tumor characteristics. Cancer Epidemiol Biomarkers Prev. 2014;23:714-24.

17. Huang X, Dugo M, Callari M, Sandri M, De Cecco L, Valeri B, Carcangiu ML, Xue J, Bi R, Veneroni S, Daidone MG, Ménard S, Tagliabue E, Shao Z, Wu J, Orlandi R. Molecular portrait of breast cancer in China reveals comprehensive transcriptomic likeness to Caucasian breast cancer and low prevalence of luminal A subtype. Cancer Med. 2015:4:1016-30.

18. Serrano-Gomez SJ, Sanabria-Salas MC, Hernández-Suarez G, García O, Silva C, Romero A, Mejía JC, Miele L, Fejerman L, Zabaleta J. High prevalence of luminal $B$ breast cancer intrinsic subtype in Colombian women. Carcinogenesis. 2016; pii: bgw043.

19. Carvalho FM, Bacchi LM, Pincerato KM, Van de Rijn M, Bacchi CE. Geographic differences in the distribution of molecular subtypes of breast cancer in Brazil. BMC Womens Health. 2014:14:102.

20. Al Tamimi DM, Shawarby MA, Ahmed A, Hassan AK, AlOdaini AA. Protein expression profile and prevalence pattern of the molecular classes of breast cancer-A Saudi population based study. BMC Cancer. 2010;10:223.

21. Preat $F$, Simon P, Noel J-C. Differences in breast carcinoma immunohistochemical subtypes between immigrant Arab and European women. Diagn Pathol. 2014;9:26.

22. Shomaf M, Masad J, Najjar S, Faydi D. Distribution of breast cancer subtypes among Jordanian women and correlation with histopathological grade: molecular subclassification study. J R Soc Med Short Rep. 2013;4:1-6.

23. Si W, Li Y, Han Y, Zhang F, Wang Y, Li Y, Linghu RX, Zhang X, Yang J. Epidemiological and Clinicopathological Trends of Breast Cancer in Chinese Patients During 1993 to 2013: A Retrospective Study. Medicine (Baltimore). 2015;94:e820

24. Kurian AW, Fish K, Shema SJ, Clarke CA. Lifetime risks of specific breast cancer subtypes among women in four racial/ethnic groups. Breast Cancer Res. 2010;12:R99.

25. Clarke CA, Keegan TH, Yang J, Press DJ, Kurian AW, Patel AH, Lacey Jr JV. Age-specific incidence of breast cancer subtypes: understanding the blackwhite crossover. J Natl Cancer Inst. 2012;104:1094-101.

26. Cherbal F, Gaceb H, Mehemmai C, Saiah I, Bakour R, Rouis AO, Boualga K, Benbrahim W, Mahfouf H. Distribution of molecular breast cancer subtypes among Algerian women and correlation with clinical and tumor characteristics: a population-based study. Breast Dis. 2015;35:95-102.

27. Alnegheimish NA, Alshatwi RA, Alhefdhi RM, Arafah MM, AlRikabi AC, Husain S. Molecular subtypes of breast carcinoma in Saudi Arabia. A retrospective study. Saudi Med J. 2016;37:506-12.

28. Cancer Incidence in Jordan-2011. Jordan Cancer Registry, 16th report. The Hashemite Kingdom of Jordan Ministry of Health, 2011.

\section{Submit your next manuscript to BioMed Central and we will help you at every step:}

- We accept pre-submission inquiries

- Our selector tool helps you to find the most relevant journal

- We provide round the clock customer support

- Convenient online submission

- Thorough peer review

- Inclusion in PubMed and all major indexing services

- Maximum visibility for your research

Submit your manuscript at www.biomedcentral.com/submit
Biomed Central 